\title{
Las trampas de la utopía: Hostos y el 98 cubano y puertorriqueño*
}

\author{
M. ${ }^{a}$ Dolores González-Ripoll Navarro \\ Centro de Estudios Históricos. CSIC
}

El artículo trata la figura y el pensamiento utópico de Eugenio M. ${ }^{a}$ de Hostos respecto de Cuba y Puerto Rico en torno a 1898, prueba dolorosa para su ideal independentista en las Antillas. Hasta entonces había combatido en dos frentes: el de la propaganda por la lucha (modélica en su opinión) que se libraba en Cuba desde 1868 y el deseo de modernización y educación de todos los habitantes de América, única manera de lograr la verdadera independencia, aquélla que conducía a una sociedad civilizada. El trabajo analiza también el eco del pensamiento hostosiano en la Cuba del siglo XX y el alcance de sus ideas de plebiscito e inevitable etapa de "americanización" en Puerto Rico.

"Con el patriotismo de las pasiones enfurecidas, con la revolución de salvarse o de morir, con los viejos heroísmos que ya han pasado de edad, con los resabios morales e intelectuales de aquel siglo pasado tan sujeto a espejismos de la mente, con eso, con lo que no sea verdad, poder y fuerza, no se irá en el siglo XX a parte alguna.

Los que no puedan llegar a alguna parte, aunque no sea más que a ser dueños de sí mismos en un rincón del espacio, que se civilicen. La orden del siglo es terminante: Civilización o muerte".

Eugenio M. ${ }^{a}$ de Hostos ${ }^{1}$

Con esta sentencia de "civilización o muerte", aparecida en 1901 en las páginas de un periódico de Santo Domingo y evocadora por otra parte de consignas más recientes, ${ }^{2}$ se resume el pensamiento final de un viejo luchador por la independencia, democratización política, educación del individuo y modernización de las sociedades americanas, que fue Eugenio

* Este trabajo fue elaborado en el marco del Proyecto PB94-0060 (DGICYT) y fue presentado en el XI Congreso Internacional de AHILA, Liverpool, 1996.

1 El Liberal, Santo Domingo, año I, núm. 170, 12 de enero de 1901, citado en Julio César López, ed.: Eugenio M. ${ }^{a}$ de Hostos, Obra literaria selecta, Caracas, 1988, pág. 348.

2 Me refiero a la frase "patria o muerte", repetidamente utilizada por la revolución cubana — sin olvidar la todavía más reciente consigna de "socialismo o muerte"- y que fuera acuñada durante la guerra de los diez años; la idea de patria que subyace en esta máxima es inherente a la noción de libertad y constituyó un valioso instrumento del discurso independentista hispanoamericano, Quijada, Mónica: “¿Qué nación? Dinámicas y dicotomías de la nación en el imaginario hispanoamericano del siglo XIX”, Imaginar la nación, Cuaderno de Historia Latinoamericana, núm. 2, 1994, págs. 15-52. 
M. ${ }^{a}$ de Hostos. ${ }^{3}$ El pensamiento que refleja esta máxima —el remedio a una muerte identificada con la barbarie de la dicotomía sarmientina-, se centra en una idea civilizadora y potenciadora de la "educación" y de la "porción culta del pueblo", frente a la ignorancia y la esclavitud que Hostos percibía en las Antillas. ${ }^{4}$ Sin embargo y como señalan algunos autores, Hostos se despojaría de pesimismo en el análisis de las sociedades antillanas al cuestionar también el modelo europeo de civilización, que tampoco había logrado sofocar la ignorancia y la barbarie; además habría que reconocerle cierto romanticismo en la opción que realizó por el hombre sencillo del campo porque, según Hostos, "los reptiles están en las ciudades". 5

Las ideas vertidas por Hostos en los últimos decenios del siglo XIX constituyeron medidas de carácter muy radical, al concretarse en reclamaciones políticas específicas contra la esclavitud y el régimen colonial español que pervivía en Cuba y Puerto Rico y a favor de la república como sistema de gobierno, la secularización de la sociedad, la renovación de los planes de enseñanza y la emulación de la vida estadounidense como ejemplo del triunfo de la civilización sobre el considerado atavismo de las tradiciones hispanas.

Estos principios marcaron, además, distintas etapas en la vida y obra de Hostos: revolucionario antillanista primero, revolucionario educativo, modernizador y antianexionista después, y una última etapa determinada por la creencia desesperanzada en el poder de la civilización como pacto entre lo ideal y lo real, entre el sueño de unas Antillas libres y soberanas pero irremediablemente abocadas a la senda modernizadora de Estados Unidos.

Eugenio M. ${ }^{a}$ de Hostos murió en el verano de 1903, el mismo año de la aprobación del Tratado de reciprocidad comercial entre Estados Unidos y Cuba, y uno después de la proclamación de la república en Cuba con la designación de Tomás Estrada Palma como presidente y la aplicación de

3 Entre la abundante producción bibliográfica sobre Hostos, véase López, Julio César: Hostos: Sentido y proyección de su obra en América, San Juan de Puerto Rico, 1995; en la misma obra, Julio César López: "Hacia un esquema de la bibliografía hostosiana”, págs. 13-28; López Cantos, Ángel: Eugenio M. ${ }^{a}$ de Hostos, Madrid, 1990; Ruano, Argimiro: Biografía de Hostos, Moca, 1993 y González-Ripoll Navarro, M. ${ }^{a}$ Dolores: Eugenio M. ${ }^{a}$ de Hostos: Utopía y federación, Colección Latinoamericanos, 4, Morelia, 1996.

4 Según Adriana Arpini en "Auto y heteroimagen en los escritos de Eugenio M. a de Hostos", Cuadernos Americanos, 46, julio-agosto, año VIII, vol. 4, 1994, págs. 239-256.

5 Fernández-Méndez, Eugenio: "El pensamiento social de Eugenio M. ${ }^{a}$ de Hostos", Revista del Instituto de Cultura Puertorriqueña, año VII, núm. 23, San Juan, abril-junio de 1964, pág. 46. 
la enmienda Platt, que fuera el inicio de una etapa de dependencia política y económica, denominada "república neocolonial" en la historiografía cubana y que se extendió hasta 1959. El espectáculo que ofrecieron las dos islas de Cuba y Puerto Rico, desde 1898 a merced de la política norteamericana - Puerto Rico era gobernada desde Washington a través de la ley Foraker aprobada en 1900-, hizo mella en Eugenio M. ${ }^{a}$ de Hostos, agotado ya de una vida entregada a la lucha por la soberanía de las Antillas y presidida por el anhelo de que la unión de las islas dada por la naturaleza se vinculase a un sistema político que lograra su supervivencia: la confederación antillana. ${ }^{6}$

Este trabajo sobre la relación de Hostos con los últimos territorios coloniales de España en el tránsito de siglo, se centra en su pensamiento y acción respecto a una y otra realidad, tanto en el período anterior a los acontecimientos de 1898 como a su consecuencia: independencias mediatizadas por la política norteamericana que, sin embargo, se producían en dos sociedades hacía tiempo distintas, que pusieron en marcha dos modos de entender la relación con el máximo exponente de la modernidad, lo que desembocaría, en la década de los años 50, en una mayor dependencia de Puerto Rico al convertirse en el Estado Libre Asociado y en la "segunda independencia cubana" que supuso la revolución de 1959. En ambos países hubo una cierta repercusión del pensamiento de Hostos, dependiendo de la coyuntura política y cultural; así, en Puerto Rico renació con la generación independentista encarnada por Albizu Campos ${ }^{7}$ y en Cuba aumentó el interés por su figura a medida que se estudiaba y ensalzaba la de José Martí (Emilio Roig de Leuchsenrig consideraría a Hostos el representante puertorriqueño del genio cubano de Martí).

6 Sobre el tema de la unión antillana, véase Reyes, A., y J. Ruscalleda: "El ideal de la Confederación de las Grandes Antillas españolas en Eugenio M. a de Hostos y José Martî", RICP, año XVI, núm. 58, San Juan, enero-marzo de 1973, págs. 39-55; Rama, C.: La idea de federación antillana en los independentistas puertorriqueños del siglo XIX, Río Piedras, 1971; del mismo autor La independencia de las Antillas y Ramón E. Betances, San Juan, 1980; Armas, R. de: "La idea de unión antillana en algunos revolucionarios cubanos del siglo XIX", Anales del Caribe, núms. 4-5, 1984-1985, págs. 140-173; Estrade, P.: "Sur les perspectives d'union des Antilles au XIX siècle", Unité et diversité

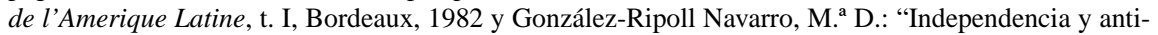
llanismo en la obra de Hostos", La Nación soñada: Cuba, Puerto Rico y Filipinas ante el 98, Aranjuez, 1995, págs. 37-47.

7 Respecto al origen ideológico de los independentistas del siglo XX puertorriqueño, es muy interesante aludir al ensayo, en su día polémico y contestado, de González, José L.: El país de cuatro pisos y otros ensayos, San Juan, 1989. Para una visión diferente véase Cortés Zavala, M. ${ }^{a}$ Teresa (Coord.): Albizu Campos y la nación puertorriqueña, 1992. 


\section{Las Antillas con y sin España}

Hostos tomó conciencia sobre la realidad antillana a muchos kilómetros de distancia ya que pasó su juventud en España, adonde fue enviado en 1852 para estudiar primero en un Instituto de Bilbao y después en la Universidad Central de Madrid. Nunca concluyó la carrera de Leyes en la que se había inscrito aunque fue muy influido por la filosofía krausista en boga en esta institución madrileña, corriente de pensamiento y moral que, junto a la corriente positivista de fines de siglo, constituyeron elementos primordiales en su evolución pedagógica y política y en su valoración de las Antillas y el futuro de América. La importancia del krausismo y del positivismo como elementos forjadores del pensamiento hostosiano ha sido puesta de relieve, entre otros, por José Luis Abellán y Manuel Maldonado Denis, quienes conciben elementos propios de un "planteamiento filosófico autónomo y con carácter ideológico específico": el krausopositivismo, que explicaría la unión estrecha del Hostos científico y del moralista "en lo más radical de su pensamiento y de su actitud humana", además de ser esta transformación "del krausista en positivista y del positivista en krausopositivista" lo que confiere a Hostos una dimensión continental. ${ }^{8}$

Algunos de estos elementos se encuentran en las primeras reflexiones de Hostos sobre las tres Antillas de tradición hispana, a las que denominó "la isla esclava" (Puerto Rico), "la isla mártir" (Cuba) y "la isla heroica"" (Santo Domingo), cuando expresaba el deseo de unidad política de estos territorios con una España que pretendía también republicana y progresista en un régimen de igualdad y autonomía. Y todavía más allá, en su deseo de confederación de las Antillas con España, sueña con una federación de todas las repúblicas americanas y de éstas con la del Norte, "porque los pueblos de América, es decir, de todo el continente, Sur y Norte, Costafirme e Islas, están llamados a formar una sola nación y a ser la admiración del mundo". ${ }^{10}$

Durante los años de estancia en España, exactamente hasta el momento en que rompió con los republicanos españoles en 1868, intentó sensibi-

8 Abellán, J. L.: "La dimensión krauso-positivista en Eugenio María de Hostos", Hostos, sentido y proyección de su obra en América, págs. 334 y 337; Maldonado Denis, M.: "Eugenio M. " de Hostos y el krausismo en América Latina", El krausismo y su influencia, Madrid, 1989, págs. 169-181. Véase también Massuh, Víctor: "Hostos y el positivismo americano", E.C. Hostos (comp.): Hostos, peregrino del ideal, París, 1954, págs. 53-75.

9 Rodríguez Demorizi, E.: Hostos en Santo Domingo, Ciudad Trujillo, 1939, pág. 2.

10 En Alba, Pedro de (prólogo): Hostos, México, 1944, pág. 62. 
lizar a la opinión pública sobre la realidad y los problemas de Cuba y Puerto Rico y, también, sobre posibles soluciones de futuro basadas en la imaginación, la lógica y la serenidad de sus postulados:

"Cuando todo el mundo me aconsejaba que no pensara en las Antillas y ellos mismos no pensaban en su libertad, yo me enajenaba la simpatía de los españoles y de los antillanos por ocuparme con constancia de mis islas. Cuando todo el mundo esperaba en España que yo utilizara la revolución a que había contribuido, por ser lógico me puse a pedir para Cuba y Puerto Rico lo que me costaba la pérdida de mi propio porvenir"."11

A esta etapa corresponde la publicación del "diario novelado" La Peregrinación de Bayoán (1863), ${ }^{12}$ texto en el que el propio Hostos-Bayoán acomete una empresa espiritual de redescubrimiento y revisión del espacio propio en busca de una identidad americana que será el fundamento de sus ideas de confederación y finalmente de inevitable separación de España:

"El patriotismo, que hasta entonces había sido sentimiento, se irguió como resuelta voluntad. Pero si mi patria política era la Isla infortunada en que nací, mi patria geográfica estaba en todas las Antillas, sus hermanos ante la geología y la desgracia, y estaba también en la libertad, su redentora". ${ }^{13}$

Resuelto a luchar por la libertad de las Antillas a partir de la libertad también en España, en lo que fue su etapa reformista, Hostos combatió en la prensa del momento por hacer oír la voz y la queja de Cuba y Puerto Rico, porque "La isla de Cuba, sujeta a la autoridad absoluta (...) es una acusación para los liberales españoles, es un borrón para el gobierno de España" ${ }^{14}$ porque "los hijos del país (de Cuba) no se contentan, como se decía, con mejoras administrativas, sino que aspiran a gozar de derechos políticos", ${ }^{15}$ porque "lo que deseamos es que Cuba y Puerto Rico sean partes integrantes de la Monarquía". ${ }^{16}$

11 Del diario de Hostos en José Ramos (comp.): Hostos en Venezuela, Caracas, 1989, pág. 121.

12 Hostos, Eugenio M. ${ }^{a}$ de: La Peregrinación de Bayoán, Madrid, 1863. Fue reeditada en 1873, Imprenta de Sud-América (Santiago de Chile) con un prólogo del propio Hostos en el que recalcaba la intencionalidad política de la obra; la última edición en Obras Completas. Edición Crítica. E. M. ${ }^{a}$ de Hostos. La Peregrinación de Bayoán. Diario recogido y publicado por E. M. ${ }^{a}$ de Hostos, Vol. I, Literatura, Tomo I, San Juan, 1988.

13 Del prólogo a la segunda edición, Chile, 1873, en E. M. a de Hostos. Ibídem, pág. 71.

14 Hostos, E. Carlos de (recop.): España y América, París, 1954, pág. 103. En esta obra se recogen más de sesenta artículos publicados por Hostos en periódicos de Madrid y Barcelona como La Soberanía Nacional, La Voz del siglo, La Nación, El Progreso, etc.

15 Ibídem, pág. 105.

16 Ibídem, pág. 171. 
A pesar del carácter integrador de la lucha, sentía cómo la cuestión de las Antillas se reducía a la isla de Cuba tanto en los debates del Congreso, como en la prensa y hasta en el sentir del pueblo, con el consiguiente olvido de Puerto Rico, cuya propia realidad no era tenida en cuenta sino como una prolongación de los acontecimientos de Cuba. En varios artículos periodísticos, como el titulado "La política" publicado en La Nación, abogaba Hostos por "una regeneración", ${ }^{17}$ por "la reforma política inmediata de Cuba y Puerto Rico", ${ }^{18}$ porque "todas las provincias de la Monarquía son hermanas (...) Abajo antagonismo" 19 y, en otros, aunando propósitos para las dos islas, incidía en el peligro que comportaba la inercia de la política española advirtiendo del peligro de no actuar a tiempo: "si es cierto que esta confianza se alimenta de la paciencia de aquellos nobles pueblos, no es menos cierto que la paciencia se acaba y, sobre todo, que ese peligro lejano, aun siendo próximo, tal vez sería menor el que hoy amenaza" ${ }^{20}$

No fue hasta después de 1868 cuando se produjo la fractura en la vida y el pensamiento hostosiano. La ruptura con la España republicana fue un trance doloroso para Hostos. En las páginas de su diario, en numerosos artículos periodísticos, dejó rastro del intento fallido de reconciliación y acuerdo respecto a la política antillana entre la familia republicana española:

"En 1868, después de la revolución de septiembre en España, (...) yo luchaba de buena fe por la libertad de España y las Antillas (...) Aproveché todas las ocasiones que se me presentaron para condenar de frente al Gobierno, la mayor parte de cuyos miembros eran mis amigos, por su conducta y la de España hacia las Antillas. Eso y el comienzo de la revolución de Cuba me decidieron a tomar una resolución definitiva" ${ }^{21}$

A punto de abandonar España para siempre, dejaba constancia de su anhelo de igualdad con América: "No olvidemos que los primeros aplausos que han saludado a la revolución española han venido del otro lado de los mares. No ha mucho que un ilustre estadista del Nuevo Mundo decía que España es también una nación americana", ${ }^{22}$ en una fecha que además del

17 Hostos, E. M. a de: 3 de marzo de 1866, en Ibídem, pág. 46.

18 Hostos, E. M. ${ }^{a}$ de: "La táctica del Gobierno con los periódicos liberales en las Antillas", La Soberanía Nacional, 7 de junio de 1866, Ibídem, pág. 58.

19 Hostos, E. M. de: "Franquicia de las harinas españolas en Cuba y Puerto Rico", La Nación, 29 de junio de 1865 , Ibídem, pág. 84. pág. 67.

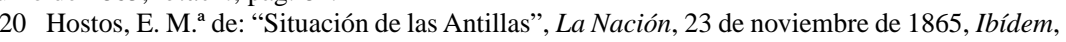

21 Nueva York, 19 de junio de 1874, en Alba, Pedro de: Hostos, pág. 111.

22 Hostos, E. M. ${ }^{a}$ de: La Voz del Siglo, 4 de diciembre de 1868, en E. Carlos de Hostos: España y América, págs. 268-269. 
principio para Cuba de una larga lucha por la independencia, fue paralela en el tiempo a la emprendida por Hostos con aspiraciones todavía más ambiciosas: independizar las islas, lograr la libertad material y espiritual de sus individuos y levantar una sociedad sobre los pilares de la educación, la justicia y la solidaridad entre los países americanos.

En definitiva, esa búsqueda de solidaridad hubo de centrarse en el apoyo a la lucha iniciada en Cuba, dado el fallido grito de Lares en Puerto Rico, y en la formulación de un programa de mayor contenido social que político para el momento de la mayoría de edad de las Antillas.

\section{Propaganda antillanista y revolución: Cuba y Hostos}

Hostos no llegó a pisar tierra cubana y tampoco conoció a José Martí, pero le hacen merecedor de la atención de todos los cubanos de ayer y de hoy tanto su personal cruzada solidaria por la lucha independentista de Cuba como su relación con algunos de sus protagonistas (Máximo Gómez y Francisco Vicente Aguilera), ${ }^{23}$ sin olvidar la incansable labor propagandista que realizó en el resto de América y sus estudios sobre la historia y los mitos literarios de la isla. ${ }^{24}$ Desde el ensayo dedicado al poeta Plácido hasta el breve recuerdo a la memoria de Aguilera, Hostos escribió acerca de hombres de la revolución como Carlos Manuel de Céspedes, Máximo Gómez, Antonio Maceo y Silverio del Prado; analizó el problema de Cuba desde diversos puntos de vista: su peso en Latinoamérica, la situación interna, la amenaza de los Estados Unidos, las estrategias bélicas inmediatas y las estrategias económicas de futuro; criticó ferozmente a los españoles a la vez que recogió maneras de sentir alternativas (el caso de cierta prensa antibelicista y de figuras como Pi y Margall y Francisco Díaz Quintero que abogaban por la pacificación, etc.); por último, y en escritos de 1902, un año antes de su muerte, Hostos mostraba cierta desconfianza en el futuro

23 Es de gran interés reseñar el hallazgo de un epistolario inédito de Hostos con cartas dirigidas a revolucionarios cubanos así como a otros antillanos relevantes por Loida Figueroa: "Eugenio M. ${ }^{\text {a }}$ de Hostos y Bonilla, según su epistolario inédito", Hostos: Sentido y proyección de su obra en América, págs. 55-92.

24 "Plácido", "Hombres de la revolución cubana", "Retrato de Francisco Vicente Aguilera", "Silverio del Prado", "Quién era Maceo", "Máximo Gómez y la revolución de Cuba" se encuentran en Hostos, E. M. ' de: Temas Cubanos (Obras Completas), vol. IX, La Habana, 1939 y reproducidos parcialmente — junto a otros textos de Hostos - en la antología de Camila Henríquez Ureña (comp. y pról.): Eugenio M. ${ }^{a}$ de Hostos. Obras, La Habana, 1976. 
de una república, la de Cuba, que había nacido mediatizada; pero en su viejo idealismo se dejaba llevar por la esperanza en el efecto civilizador que suponía el sistema político norteamericano.

Profundizando en el pensamiento y obra de Eugenio M. ${ }^{a}$ de Hostos sobre Cuba, hay que decir que en su peculiar visión de los hombres y de sí mismo, Hostos se identifica con muchas de las cualidades que atribuye a las figuras que analiza y ensalza. ${ }^{25}$ Hostos es Plácido, el poeta ajusticiado por su implicación en una revuelta de esclavos en la isla en $1842,,^{26}$ en el común descubrimiento de un deber, ${ }^{27}$ en la lucha por la libertad y la justicia dejando atrás la creencia en las bondades del sistema colonial, elementos que a su vez asimila al estado de Cuba, porque "no podríamos leer sin invencibles repulsiones de estómago las páginas consagradas por Plácido a enaltecer la indignidad (...) la peor de las situaciones en que puede estar un pueblo esclavo: contento con su amo". ${ }^{28}$

Hostos será Carlos Manuel de Céspedes, primer presidente de Cuba, que como él fue enviado a estudiar a Europa y "viajó, vio, deseó y volvió más cubano que había ido", ${ }^{29}$ y al que aprecia sobre todo en lo que hace grandes a los hombres, en lo que hizo grande a Céspedes: su utilidad a la humanidad. ${ }^{30}$ Se fundirá en los deseos de acción de Francisco V. Aguilera y en el patriotismo del general Silverio del Prado "verdadero cubano en la época de la revolución que tantos falsos cubanos malparió". ${ }^{31}$ Hostos será Maceo y Gómez en su dimensión de soldados y ciudadanos ejemplares.

Si bien la imagen de España como encarnación del mal, del infierno, de todos los horrores posibles, está muy presente en los escritos de Hostos durante la guerra de los diez años, hay un pecado que, según Hostos, no han

25 Un ejemplo en los análisis sobre la relación entre Hostos y Hamlet (prestigioso ensayo de Hostos) de Luis Villaronga: "Hostos personaje hamletiano" y F. Hernández de León: "Hamlet y Hostos", ambos artículos en Hostos, E. Carlos de: Eugenio M. ${ }^{a}$ de Hostos. Peregrino del Ideal, París, 1954, págs. 211-217 y págs. 218-221, respectivamente. El concepto abarcador de Hostos respecto a la literatura es señalado por Marcos Reyes Dávila: "Hostos: la llamarada escrituaria”, en Hostos: Sentido y proyección, págs. 553-566.

26 “A dónde va? [el hombre fuerte y valeroso] No importa a donde va. Va, y eso es lo que importa. Irá, como Plácido, al suplicio (...); irá, como el combatiente cubano, hacia la independencia; irá como los puertorriqueños errantes, hacia la revolución”, Hostos, E. M. a de: Temas cubanos, pág. 48.

27 "Ya Plácido ha comprendido que hay un deber en cada vida y que de los cumplidores de ese deber es la consecución de su objeto y la realización de su destino", Ibídem, pág. 52.

28 Ibídem, pág. 25.

29 Ibídem, pág. 120.

30 "Para mí no hay grandes hombres. Son útiles o inútiles para la humanidad y se acabó", Ibídem, pág. 121.

31 Ibídem, pág. 154. 
cometido los españoles: “ $¡$ no han podido hacer hijos españoles. Se mezclaron con los indios y salieron cubanos; con los negros y salieron cubanos, con las mulatas y salieron cubanos, con extranjeros y salieron cubanos; los mandaron a España a olvidar a Cuba y volvieron a Cuba maldiciendo a España". ${ }^{32}$

El juicio que le merece entonces la política de la primera república española es similar a la opinión de José Martí para ese mismo momento histórico, en el sentido de que la República española, mediante su política antillana, de libertadora se convertía en liberticida. Para combatirla, Hostos llega a Nueva York en la primavera de 1874, atraído por la noticia de que se preparaba una expedición para libertar Puerto Rico, viaje de regreso a América que sería definitivo tras una breve estancia en París, donde tuvo ocasión de conocer a muchos cubanos emigrados que le parecieron "refugiados del placer" que buscaban en esta ciudad lo que habían perdido en La Habana. ${ }^{33}$ El resto del exilio antillano que fue conociendo poco a poco le decepcionó profundamente por su carencia de ideas y de coordinación, por estar dividido y receloso. Si la emigración de Nueva York era una ruina, la de Nueva Orleans se había fatigado o había perdido la fe, y la de Puerto Plata no obedecía a planes eficaces: en 1874 exclamaba:

\begin{abstract}
"hace seis años que empezó el martirio de Cuba. ¿Ha faltado el dinero? centenares de cubanos poderosos hubieran podido ofrecer a su patria una parte de los bienes que deben. Han faltado otras cosas importantes en la revolución como el dinero. Ha faltado fervor; ha faltado oportunidad en los donativos patrióticos; ha faltado elevación del alma; ha faltado el olvido de sí mismos, que es por donde empiezan y concluyen las revoluciones, que es el arma con que se asegura la victoria". ${ }^{34}$
\end{abstract}

Pero el combate más importante que hubo de librar Hostos en Nueva York fue contra el brote anexionista que se percibía en el gobierno y la opinión pública norteamericana e, incluso, entre las filas del movimiento cubano. Quizás porque, como bien señalaba Betances, "los cubanos no han querido ver en el mundo más que a los americanos. Es lo que los pierde". ${ }_{35}$

32 "Cuba", Ibídem, pág. 178.

33 "Cayo Hueso", Ibídem, pág. 251. Sobre la estancia de Hostos en París, consúltese Vázquez, Carmen: "Los trabajos y los días. Hostos en París (1868 y 1869)", en Hostos: Sentido y proyeccion de su obra en América, págs. 165-182, y para una visión general del exilio cubano véase el estudio de Estrade, P.: La colonia cubana de París, 1895-1898. El combate patriótico de Betances y la solidaridad de los revolucionarios franceses, La Habana, 1984, donde menciona algunos artículos que Hostos hizo llegar desde Santiago de Chile en 1897.

34 "10 de octubre", Temas Cubanos, pág. 127.

35 H. Dilla y Godínez, E., (Selec. y Pról.): Ramón Emeterio Betances, La Habana, 1983, pág. 29. 
Un año más tarde, en 1875, tiene Hostos la oportunidad de unirse a la expedición que estaba preparando el cubano Francisco Vicente Aguilera y escribe: "Han venido a preguntarme si estoy dispuesto a emprender otra vez la aventura. He dicho que sí. Voy preparándome para salir pasado mañana. Será una locura, pero es preferible ser un loco a vivir entre esta gente" ${ }^{36} \mathrm{La}$ expedición, compuesta por cuatro revolucionarios y seis marineros, partió del puerto de Boston en el vapor Charles Miller, pero se frustró a los seis días por las adversas condiciones meteorológicas y la infiltración de agentes enemigos que traicionaron el plan: " $i Q u e ́$ barco para una aventura! — se lamentaba Hostos - No quiero hacer comentarios. Solamente quiero expresar mi intención: no emprenderé aventuras de que yo mismo no sea el director. El ridículo es demasiado grave cuando es el resultado de una tentativa heroica". ${ }^{37}$

Sin embargo, su colaboración con los cubanos de la emigración continuará con la codirección, junto al escritor cubano Enrique Piñeyro, del periódico El Mundo Nuevo-La América Ilustrada, ${ }^{38}$ donde describirá la situación de Cuba como un problema latinoamericano que afecta, directa o indirectamente, a todo el continente. La estrategia que Hostos propone pasa por plantear los elementos que tienen Cuba y las demás Antillas centrales para alcanzar y conservar la independencia, el modo de salvar los obstáculos que se oponen y las bases en que debe reconstituirse la sociedad cubana y el resto de sociedades del archipiélago.

La lucha por la independencia de Cuba llevará a Hostos, en esta estrenada etapa de madurez política, a pisar las Antillas en lo que fue su primer viaje a Santo Domingo en la primavera de 1875, para establecerse en la ciudad de Puerto Plata. Regresó a Nueva York en 1876 y continuó sus tareas periodísticas con la publicación de siete artículos en el semanario de la emigración cubana La Voz de la Patria, que constituyen un corpus político, el denominado Programa de la liga de los Independientes, cuyo objetivo era trabajar material, intelectual y moralmente en favor de la independencia absoluta de Cuba y Puerto Rico, hasta conseguir su total separación de España y su indiscutible existencia como naciones soberanas. ${ }^{39}$

36 Roig de Leuchsenring, E.: Hostos y Cuba, La Habana, 1974, pág. 46. La primera edición fue publicada en la Colección Histórica Cubana y Americana, La Habana, 1939.

37 Hostos, E. M. ${ }^{a}$ de: Diario, OC, vol. II, pág. 217.

38 Hostos escribió sin firma, con su nombre y bajo diversos seudónimos, artículos como "El problema de Cuba", "Guillermo Matta", "En la tumba de Segundo Ruiz Belvis", etc. En Hostos: Eugenio M. ${ }^{a}$ de Hostos. Peregrino del ideal, pág. 414.

39 "La Liga de los Independientes", artículos publicados los días 13, 20, 27 de octubre y 3, 10,

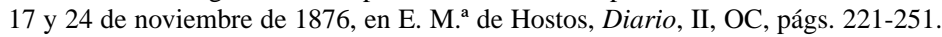


El José Martí de "Nuestra América" los conoció en profundidad y desde México dedicó unas reflexiones, con el título significativo de "Catecismo democrático" ${ }^{40}$ a estas propuestas de Hostos para establecer en las Antillas un régimen político asentado en los principios de libertad, autoridad de las leyes, igualdad, separación de poderes, nacionalidad y expansión:

"E. M. ${ }^{a}$ de Hostos es una hermosa inteligencia puertorriqueña cuya enérgica palabra vibró rayos contra los abusos del coloniaje, en las cortes españolas, y cuya dicción sólida y profunda anima hoy las columnas de los periódicos de Cuba Libre y Sur América que se publican en Nueva York. (...) en tiempo de convulsiones políticas, nunca está de más la palabra que recuerda cómo el principio de soberanía, que es la expresa e incontestable voluntad de todos, es el único que puede ya regir a un pueblo como el nuestro, habituado a ejercer con energía y sin contradicción su voluntad". ${ }^{41}$

Hostos concluiría años más tarde que su programa sirvió a Martí como base para la fundación del Partido Revolucionario cubano en 1892 y para el Manifiesto de Montecristi en 1895.42

Con el inicio de la guerra en Cuba en 1895, Hostos escribe: "Cuba está frente a España no ya desde febrero de 1895 sino desde octubre de $1868,(. .$.$) el intervalo entre 1879$ y 1895 ha sido una verdadera tregua de guerra" ${ }^{43} \mathrm{Y}$ volverá por sus fueros revolucionarios con el cargo de Agente de la Junta del Partido Revolucionario de Cuba y Puerto Rico de Nueva York en Santiago de Chile, con su labor como socio correspondiente del Centro Propagandista Cubano Martí de Caracas, y convertirá nuevamente la tribuna periodística en azote contra el colonialismo español y el peligro que representaba para el porvenir de las Antillas la presencia expansionista de los Estados Unidos. Además de trabajar como director de la Sociedad Unión Americana (pro Cuba) en Santiago, formó, junto a otros siete cubanos, el denominado "Círculo Revolucionario Cubano" que emprendió una labor propagandista de la revolución en la prensa que tuvo muchos

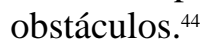

40 "El Federalista", 5 de diciembre de 1876, México. Reproducido por Revista de la Biblioteca Nacional, Cuba, tomo IV, núm. 3, La Habana, julio-septiembre de 1953, págs. 26-28.

41 En Martí, J.: Obras Completas, vol. 8, La Habana, 1975, págs. 53-54.

42 En Maldonado-Denis, M.: Eugenio M. ${ }^{a}$ de Hostos y el pensamiento social iberoamericano, México, 1992, quien concluye que Hostos y Martí "concebían la revolución antillana como democrática, republicana, populista, anticolonialista y antiimperialista", pág. 67.

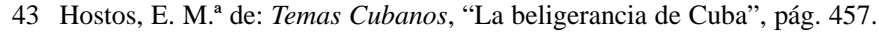

44 Roig de Leuchsenring, E.: Hostos y Cuba, pág. 162. 
En el otoño de 1897, Hostos retoma la pluma para ensalzar la lucha independentista cubana en treinta y dos cartas públicas, dirigidas al senador Guillermo Matta y publicadas en la prensa de Chile y de la República Dominicana, sobre el derecho de Cuba a su independencia, como primera etapa de la Confederación antillana y de la exigencia de solidaridad al resto de las repúblicas americanas. ${ }^{45}$ Tienen mucho interés porque Hostos madura su juicio sobre la situación de las Antillas y ofrece elementos diversos para su análisis, aun desde la lejanía y el conocimiento de la realidad a través de la prensa y el telégrafo, artefacto convertido en su opinión en arma psicológica de los españoles contra los independentistas: "todo lo veremos en los despachos telegráficos; pero no veremos resuelto el problema de Cuba [Porque los cubanos revolucionarios] No combaten, no resisten, no triunfan contra un enemigo superior en fuerza numérica, en disciplina orgánica, en recursos pecuniarios, militares y sociales, combaten, resisten, triunfan contra las fuerzas ciegas de la naturaleza, utilizadas por la civilización y entregadas por la iniquidad a sus contrarios". ${ }^{46}$

Pero las preocupaciones de Hostos seguían siendo de índole general; ya había dirigido otra carta al general dominicano Gregorio Luperón, expulso entonces en Saint Thomas, incitándole a dirigir "el movimiento de las Antillas que Cuba ha vuelto a iniciar" ${ }^{\prime 47}$ y señalando que si la independencia de Cuba sobrevenía sin que Santo Domingo estuviera libre de la dictadura que todavía padecía, Puerto Rico seguiría esclava y la soñada confederación se tornaría un sueño imposible.

En Estados Unidos la opinión pública era cada vez más favorable a la intervención en el Caribe, amenaza que se concretó con la llegada a la Casa Blanca del presidente Mckinley en 1897 —representante del grupo más expansionista del Congreso- y que se consumó con la voladura del acorazado "Maine" durante su visita al puerto de La Habana y con un ultimátum que exigía al gobierno español que en el plazo de tres días renunciase a sus derechos de soberanía en Cuba. La guerra emprendida se saldó con anexiones e independencias nominales de las últimas colonias españolas, tanto en América como en Asia, a favor de los Estados Unidos.

45 Llevan el subtítulo de "Cuba ante América. Examen crítico del conflicto hispano-americano y del derecho de Cuba a la Independencia”, en Hostos, E. M. a de: Temas cubanos, págs. 341-453.

46 "10 de octubre", Ibídem, pág. 128.

47 Bosch, J.: Hostos, el sembrador, La Habana, 1939, pág. 162. 


\section{Eco de la figura de Hostos en Cuba}

El eco de la figura y la obra de Hostos en las Antillas ha sido desigual en el tiempo y en los elementos resaltados por la historiografía de cada país, aunque los calificativos y sobrenombres que se le han atribuido son elocuentes del interés que ha despertado su pensamiento y su obra: "el sembrador", "el sembrador apasionado", "ciudadano de América", "peregrino del ideal", "hombre de América", "apóstol de la libertad", "promotor del Panamericanismo", "revolucionario", "el antillano", "vivir peregrinante en confesión", "voz de América", "el olvidado", "sembrador sin cosecha", etc.

En la isla de Cuba, se hizo muy temprano una semblanza de Hostos en las páginas de Cuba Contemporánea ${ }^{48}$ y en 1938 se creó una Comisión Cubana Pro Centenario de Hostos a celebrarse el año siguiente en Puerto Rico. Fue precisamente en La Habana donde se realizó la primera edición de las Obras Completas de Hostos con ocasión del centenario de su nacimiento, año en que también vieron la luz muchos otros trabajos, tanto ensayos biográficos como publicación de escritos suyos ${ }^{49}$ con el sentimiento que Cuba, al unirse a esa gloriosa rememoración, saldaba una vieja deuda que tenía pendiente con Hostos.

El historiador cubano Emilio Roig de Leuchsenring publicó en 1953 Puerto Rico en lucha por su independencia ${ }^{50}$ donde criticaba, sin embargo, cómo el régimen colonial e imperialista de Estados Unidos había celebrado el centenario de Hostos en 1939, resaltando su faceta de pedagogo, sociólogo y jurista y ocultando al verdadero "defensor incansable de la independencia y libertad de Cuba y Puerto Rico". ${ }^{51}$ Escrita en el centenario del nacimiento de Martí, la obra de Roig la dedica a quienes están en continua lucha por convertir a Puerto Rico en una República independiente y soberana.

Es interesante destacar la repercusión de la figura y el pensamiento de Hostos no sólo en la historiografía sino en algunas instituciones y agrupaciones políticas de Cuba y, sobre todo, entre los nacionalistas puertorriqueños

48 Blanco Fombona, Rufino: "Eugenio M. ${ }^{a}$ de Hostos", Cuba Contemporánea, abril, tomo 4. núm. 4, año II, págs. 400-427.

49 América y Hostos, La Habana, 1939; Bosch: Hostos el..., La Habana, 1939; Estenger, Rafael: Sociopatía americana. Comentarios a Hostos, La Habana, 1939; Roig de Leuchsenring, E.: Hostos, apóstol de la Independencia y de la libertad de Cuba y Puerto Rico, Cuaderno de Historia Habanera, núm. 17, La Habana, 1939.

50 Roig de Leuchsenring, E.: Puerto Rico en lucha por su independencia, La Habana, 1984, (1. ${ }^{\mathrm{a}}$ ed. en 1953).

51 Ibídem, pág. 59. 
del siglo XX. Inspirándose en la figura de José Martí y en cómo el libertador unía siempre los nombres de Cuba y Puerto Rico, Roig resalta en algunas obras la proyección internacional como elemento clave de la lucha por la soberanía nacional (El internacionalismo antiimperialista en la obra político-revolucionaria de José Martí, ${ }^{52}$ Martí antiimperialista $a^{53}$ y La revolución de Martí. 24 de febrero de 1895 con notas para un ensayo biográfico. ${ }^{54}$

Si no pudo consumarse la confederación de las Antillas, sí podríamos referirnos al menos - a través del vínculo entre Martí y Hostos-, a una "federación de ideas" por encima de las personas que las encarnaron a lo largo del siglo XX, ya que el continuo apoyo de Hostos a los rebeldes cubanos se proyectó luego en las acciones de ciertos antillanos inconformistas, de puertorriqueños como Matienzo Cintrón, fundador en 1911 del Partido Independentista, de José de Diego, de integrantes del Partido Nacionalista como Ramón Mayoral Bandrés, Antonio Vélez Alvarado y por supuesto Pedro Albizu Campos, quienes optaron por batirse en la arena política, más en la línea de Martí que de Hostos. ${ }^{55}$

En Cuba, a su vez, se mantenía la solidaridad con Puerto Rico a través de comités de apoyo en los que participó Roig de Leuchsenring, y que evocan los numerosos que fundó Hostos por toda América continental como la Sociedad de Auxilios para Cuba, fundada en Lima en 1871, en Valparaíso en 1872 y la Sociedad Pro Independencia de Cuba creada en Buenos Aires en 1873. En 1927 se constituyó la Junta Nacional Cubana Pro Independencia de Puerto Rico, presidida hasta su muerte por Enrique José Varona, y que dio lugar a otras asociaciones afines como la comisión creada por el propio Roig en 1938 para conmemorar el nacimiento de Hostos, la Comisión Cubana pro Centenario de Hostos, que realizó un llamamiento al presidente Roosevelt solicitando la libertad de Albizu Campos y la independencia y libertad de Puerto Rico. ${ }^{56}$

Un año más tarde, durante la estancia de la esposa del líder nacionalista Albizu Campos en Cuba, se fundó el Comité Cubano Pro libertad de Patriotas Puertorriqueños para llevar sus exigencias a todos los foros políticos americanos. A estas agrupaciones se unió otra de menor carácter político, pero no menos militante con la causa independentista y antiimperia-

52 La Habana, 1984 (1. a edición, 1935).

53 Roig de Leuchsenring, E., La Habana, 1961.

54 Cuadernos de Historia Habanera, 1941.

55 Maldonado-Denis, M.: Puerto Rico: mito y realidad, San Juan, 1973.

56 Roig de Leuchsenring, E.: "El deber cubano de continuar luchando por la independencia y libertad de Puerto Rico", Puerto Rico en lucha por su independencia, págs. 13-19. 
lista, que era la Sociedad Cubana de Estudios Históricos e Internacionales presidida por el propio Roig de Leuchsenring y que no dejó de formular protestas y reclamar atención sobre la situación de Puerto Rico

Con la revolución cubana de 1959, las ideas se radicalizan y la figura de Hostos parece ser clave, entonces, para entender el propio proceso interno de Cuba: una historia revolucionaria que se hace arrancar desde 1868 y que necesita de claves e ideas en las que asentar la nueva lucha contra el imperialismo norteamericano y por la libertad (ya Hostos distinguió entre la consecución, primero, de la independencia, y después de la libertad), en la idea de que si Cuba ha pasado ya por una independencia mediatizada le ha llegado el momento de la libertad con la revolución y vuelve su mirada a aquellos que lo soñaron antes. Así, en los primeros años de la revolución se privilegió la reedición de las obras históricas de la generación de los cuarenta, por lo general académicos en ejercicio ligados al movimiento revolucionario; y un claro ejemplo fue el trabajo emprendido por E. Roig de Leuchsenring ${ }^{57}$ como encargado de la Oficina del Historiador de la ciudad de La Habana, desde donde se promovió la publicación de obras que respaldaran el espíritu nacional y antiimperialista, además de la exaltación del momento histórico que se vivía, iniciándose también, como se ha visto, la divulgación del pensamiento de Martí..$^{58}$

Hasta los años setenta no vuelve el interés por Hostos al reeditarse, en 1974, el volumen titulado Hostos y Cuba,$^{59}$ que había sido publicado en 1939 y en el que Emilio Roig de Leuchsenring recogió muchos de los escritos de Hostos sobre Cuba, así como trabajos de Lino D’Ou, Medardo Vitier y de su autoría.

En la recopilación de Roig se ponía de manifiesto el carácter precursor de Hostos en la obra de Martí, el olvido e ingratitud de los cubanos hacia él y su énfasis en las previsiones antiimperialistas, "consejo oportunísimo que Hostos nos envía en estos momentos tan difíciles por el confusionismo y las contradicciones imperantes en la actual situación de

57 Almodóvar, C.: Antología crítica de la historiografía cubana (período neocolonial), 1989; la misma autora en "Historiografía realizada en Cuba después de la revolución "castrista" (19591984)", Revista de Indias, 1989, vol. XLIX, núm. 185, págs. 173-191, destaca su labor al frente de la Oficina del historiador de la ciudad de La Habana con títulos como: Males y vicios de Cuba republicana (1959), El antiimperialismo de D. Francisco Hernández y Carvajal (1959), Los Estados Unidos contra Cuba libre (4 t., 1959), etc.

58 Cortés Zavala, T.: "Análisis historiográfico de Cuba contemporánea”, Cuba. Algunos problemas de su historia, Praga, 1995, págs. 47-58.

59 Roig de Leuchsenring, E.: Hostos y Cuba, La Habana. 1974. 
Cuba" ${ }^{60}$ Es de resaltar también la publicación en 1976 de una selección de las obras de Hostos a cargo de Camila Henríquez Ureña por la Casa de las Américas ya mencionada.

En 1986 José A. Benítez destacaba a Hostos como uno de los mártires del continente americano que más luchó por su pueblo, un hombre consagrado a la libertad, la dignidad, la solidaridad y la internacionalización del movimiento revolucionario, ${ }^{61}$ dentro de lo que sería una búsqueda de la "patria grande". La importancia de esta obra es que señala la vigencia de su pensamiento en una realidad diferente, arma del pasado forjadora de un futuro, ideas que, según Benítez "pueden también estar referidas a la situación actual de América Latina en el campo de la educación, de la unidad necesaria frente al enemigo común, del patriotismo, de las causas populares, de la revolución latinoamericana, del internacionalismo, de la segunda independencia del continente. (...) Esas ideas que nos legaron indican el camino a seguir ahora". ${ }^{62}$ Con el fin de recuperar y difundir el legado hostosiano en Cuba, hay que señalar el interés de la publicación de los fondos depositados en la Biblioteca Nacional José Martí relativos a Hostos con ocasión del sesquicentenario de su nacimiento.$^{63}$ Para finalizar, señalar que muy recientemente Jorge Ibarra, en referencia a la cultura e identidad nacional puertorriqueña en relación con la cubana, señalaba cómo Puerto Rico "ha resistido los embates de la ocupación colonial estadounidense (...) ha defendido su lengua, su cultura y su manera de ser, frente a la penetración cultural anglosajona". ${ }^{64}$

\section{Hostos y sus ideas de plebiscito y modernización para Puerto Rico}

De sus Obras Completas, publicadas por primera vez en 1939, es el volumen V el que está dedicado a la campaña política por Puerto Rico, volumen titulado "Madre Isla" y que abarca desde 1898 a 1903. Ya se ha hecho mención del poco tiempo que Hostos residió en su tierra; precisa-

\footnotetext{
60 Ibídem, pág. 100.

61 Benítez, José A.: El pensamiento revolucionario de hombres de nuestra América, La Habana, 1986.

62 Breve texto en la contraportada, Ibídem.

63 García Carranza, A.: Eugenio $M^{a}{ }^{a}$ de Hostos en la Biblioteca Nacional José Martí. Bibliografía, La Habana, 1988.

64 Ibarra, J.: "Cultura e identidad nacional en el Caribe hispánico", La Nación soñada: Cuba, Puerto Rico y Filipinas ante el 98, pág. 95.
} 
mente en estos años críticos del cambio de siglo estuvo en Puerto Rico durante poco más de un año. Había llegado en septiembre de 1898 (la bandera estadounidense se izó por vez primera en el mes de julio) y lo había hecho vía Nueva York; pero desde Chile, donde llevaba diez años viviendo $y$ trabajando en el campo educativo. ${ }^{65}$ Tras casi veinte años de ausencia, regresaba Hostos a su Madre Isla con el fin de poner en acción a sus habitantes. En su diario de viaje dice experimentar "una alegría conturbada por una tristeza llena de indignación": "pensaba en lo noble que hubiera sido verla libre por su esfuerzo y en lo triste y abrumador y vergonzoso que es verla salir de dueño en dueño sin jamás serlo de sí misma y pasar de soberanía en soberanía sin jamás usar de la suya". ${ }^{66}$

En Puerto Rico asistió a lo largo de 1899 a ese cambio de soberanía cuyo símbolo puede ser el huracán que asoló la isla en agosto de 1899, "último del siglo XIX y primero bajo mandato americano" y, cuyo efecto devastador, señala la historiadora puertorriqueña Irene Fernández Aponte, podría tener mucho que ver con ese cambio ya que, hasta entonces, los avisos meteorológicos venían del observatorio del Colegio de Belén de La Habana y los norteamericanos lo cambiaron a San Juan. En el momento de producirse el huracán ya estaba interrumpido el servicio con Cuba y, al parecer, no se recibió y difundió a tiempo la noticia. ${ }^{67}$

Hostos abandonaría para siempre la isla de Puerto Rico en enero de 1900 al ser llamado por el presidente de la República Dominicana con el objeto de confiarle la mejora de la educación; y allí trabajaría los escasos años que le quedaban de vida ya que murió en 1903. En una carta al presidente dominicano Horacio Vásquez, escribía Hostos en septiembre de 1899:

"La patria se me escapa de las manos. Siendo vanos mis esfuerzos de un año entero por detenerla...el ideal...la Confederación de las Antillas...ése es el porvenir positivo de las Antillas ...el lógico propósito de nuestra vida es, como debe ser, constituir una confederación de pueblos insulares que ayuden a los pueblos continentales de nuestro hemisferio occidental a completar, extender y sanear la civilización". ${ }^{68}$

Un año de permanencia en su tierra natal había sido suficiente para asistir a cambios como la aprobación del Acta Foraker. Con ella se suprimía el régimen autónomo concedido por España en 1897, que había establecido

65 Araya, Juan G.: Eugenio M. ${ }^{a}$ de Hostos en Chile, Chillán, 1987.

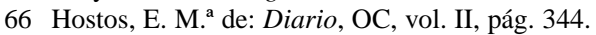

67 Fernández Aponte, I.: El cambio de soberanía en Puerto Rico, Madrid, 1992, pág. 160.

68 En Henríquez Ureña: Eugenio M. ${ }^{a}$ de Hostos. Obras, pág. 499. 
una cámara de representantes y un consejo de administración, preservando la representación en las Cortes y decretando la ampliación de las atribuciones de la Diputación Provincial. De este modo, el gobierno de España sólo mantenía sobre la colonia las facultades inherentes a la soberanía, habiéndose otorgado por fin el derecho de Puerto Rico a fijar su propio arancel, firmar tratados comerciales y establecer su propio presupuesto. Las imposiciones de la nueva situación tuvieron rápidamente consecuencias y en el caso de la tarifa arancelaria de Estados Unidos en Puerto Rico barrió las artesanías e incipientes industrias locales, produjo el definitivo desplazamiento del café puertorriqueño del mercado europeo y ocasionó nuevas disposiciones como la devaluación del peso, congelación de créditos y fijación de precios de la tierra al nivel de Estados Unidos que dificultaron la situación.

Por tanto, desde la firma del Tratado de París de 1898 por el que Cuba obtenía una independencia mediatizada y Puerto Rico pasaba a los Estados Unidos, y desde que impusieron un gobierno militar (1898-1900) y más tarde la Carta Orgánica aprobada por el Congreso Norteamericano - la mencionada ley Foraker de 1900 mediante la cual el poder legislativo se ejercía desde Washington- ${ }^{69}$ Hostos captaba la anexión de la isla a Estados Unidos, asumiendo una posición teñida de desconfianza y beligerancia, por una parte, y de admiración por otra: "la invasión de Puerto Rico por las armas norteamericanas tiene por confeso objeto la anexión de la isla (...) Lo único que se me presenta como seguro es que el gobierno americano, al resolver, tomará en cuenta la voluntad de la isla". ${ }^{70}$

La solución concebida por Hostos para que Puerto Rico alcanzara la verdadera civilización y venciera "los obstáculos que [a ella] opone la tradición española", ${ }^{11}$ fue la creación de la denominada "Liga de Patriotas" con un objetivo social a corto plazo y de gran alcance (formar a la juventud para el futuro), y uno político que sería más una consecuencia natural de aquél. En su primer manifiesto público sobre los propósitos de la liga en Nueva York, de la que Hostos es nombrado presidente y Roberto H. Todd secretario, se señalan los dos fines de su constitución: "uno, inmediato, que es el poner a nuestra Madre Isla en condiciones de derecho; otro, mediato, que es el poner en actividad los medios que necesitan para educar a un pue-

69 Luque, M. ${ }^{a}$ D.: La ocupación norteamericana y la Ley Foraker, Río Piedras, 1980.

70 Ambos textos en sendas cartas enviadas por Hostos desde Washington, el 27 de julio de 1898 a Francisco Arredondo y a Marías Vidal, en Henríquez Ureña, C.: E. M. ${ }^{a}$..., págs. 480-481.

71 Hostos, E. M. ${ }^{a}$ de: Madre Isla, OC, vol. pág. 316, alude en innumerables ocasiones a la necesidad de "salir del pasado ibérico y entrar en el porvenir americano", "dejar de ser representantes del pasado y ser hombres de nuestro tiempo y sociedad del porvenir", pág. 8, etc. 
blo en la práctica de las libertades que han de servir a su vida, privada y pública, industrial y colectiva, económica y política, moral y material". ${ }^{22}$ La primera liga fue instaurada en Ponce con no demasiado éxito; en una carta a Federico Henríquez Carvajal señalaba Hostos que "la tarea de la liga de patriotas, que trascenderá con el tiempo en Quisqueya y Cuba, cuesta imponderablemente en Borinquen; pero va...". ${ }^{73}$ Cuando se conocen y discuten los estatutos de la liga en Ponce, Juana Díaz y Yauco, sus habitantes disienten en algún punto al pensar que el fin último de la liga puede llegar a ser la independencia, objetivo por el que no están dispuestos a luchar. Resultado de todo ello es que Hostos tratará de "llegar a hacer entender (...) de qué independencia, tan distinta de la que anhelábamos contra España, puede algún día, para bien de todos, continente e islas, llegar a ser necesario, práctico y económico ocuparse". ${ }^{74}$ Los estatutos de la Liga pretendían la toma de conciencia por parte del pueblo, no la toma del poder como el Partido Revolucionario Cubano de Martí. Sus propósitos educadores y cívicos muestran claramente el idealismo hostosiano: "claro está que la liga de patriotas no es un partido ni puede ser partido, no quiere ser partido. No por eso deja de tener una política, pero absolutamente subordinada a su propósito social que es el formar un pueblo. Maldito, si a quien tiene tal propósito se le puede ocurrir hacer política". ${ }^{75}$

Hasta tal punto el objetivo de la liga era amplio y su filosofía nada sectaria, que agrupó tanto a partidarios de la anexión — la mayoría — como al reducido número de los que, como señala Hostos con cautela y cierto eufemismo, eran "conocedores de la necesidad de independencia" ${ }^{76} \mathrm{y}$, finalmente, sostenedores de un gobierno temporal de Estados Unidos en Puerto Rico "para americanizar, es decir, para poner al pueblo puertorriqueño en aptitud de vivir a la manera del pueblo americano". ${ }^{77}$

La liga de patriotas defendió la convocatoria de un plebiscito para que el pueblo puertorriqueño pudiera decidir sobre la situación de anexión, tachada por Hostos de contraria "al desarrollo del sistema americano de

72 Fragmento del manifiesto "A los puertorriqueños", Nueva York, 10 de septiembre de 1898, en González, J. E.: Vivir a Hostos, San Juan, 1989, pág. 142.

73 Carta fechada el 21 de noviembre de 1898, en E. M. ${ }^{a}$ de Hostos: Madre Isla, pág. 251.

74 Henríquez Ureña: E. M. ${ }^{a}$ de Hostos..., pág. 487.

75 Hostos, E. M. a de: Madre Isla, pág. 29.

76 Ibídem, pág. 15.

77 Ibídem, págs. 32-33. Véase el interesante trabajo de Luis Agrait: "Puerto Rico en el vórtice del '98: "A prisa, a toda prisa, formemos la patria", La Nación Soñada:... págs. 97-107, que señala cómo hasta Hostos incorporaba en su programa de la liga de patriotas la idea del gobierno temporal llevado por la confianza y el conocimiento del derecho norteamericano. 
gobierno, (...) sujeción violenta de Puerto Rico a una dominación que, por salvadora que sea, para nada ha contado con Puerto Rico". ${ }^{78}$ Los artículos que tratan del plebiscito están también publicados en el volumen V "Madre Isla", y parece que surgieron de la pluma de Hostos como respuesta a un comentario de un periódico ponceño, en el que se trataba de ridiculizar los argumentos a favor de esta solución formulada por la liga de patriotas. ${ }^{79}$

Hostos integraba en su defensa del "plebiscito como política" la crítica a la falta de ética de Estados Unidos, ya que "a la cesión no debió seguir una transferencia de dominio, sino una consulta de la voluntad de Puerto Rico" porque "una anexión forzada es una agresión criminal", y defendía la solicitud de un gobierno temporal de los Estados Unidos "no por el prurito de constituir nación, sino por devoción profunda a la civilización":

"cuando hayamos conseguido el plebiscito, acataremos la anexión si ésa es la voluntad de Puerto Rico; y si su voluntad es otra, daremos a la federación del Norte el mejor de cuantos homenajes pueda recibir un pueblo de justicia pidiéndole un protectorado temporal de 20 años que, para mayor gloria suya y honra nuestra, no será un protectorado de fuerza y poder, sino un mentorado de libertades y progresos" ${ }^{80}$

En la visión que tendrá Hostos del nuevo orden de cosas hay que tener en cuenta, como en otras ocasiones, que el Hostos intelectual y moralista opacará al Hostos político y revolucionario. Así realizará, en un principio, continuas alabanzas al presidente McKinley en la idea de que el panorama

"establecido en nuestra madre Isla por la Ley Foraker o 'Ley de gobierno civil para Puerto Rico', es un orden viejo y nuevo a la vez; viejo, en cuanto conserva fundamentos de coloniaje; nuevo, en cuanto efectivamente contiene de régimen civil a la americana. Lo que se debe hacer es ayudar al régimen civil a acabar de arrojar de la isla al régimen colonial", ${ }^{81}$

Hostos defiende, en última instancia, la modernización de Puerto Rico, proyecto sinónimo de americanización, idea considerada de modo global como un proceso de cambio económico que modificara la organización social, sustituyera los principios organizativos de la política española

78 Henríquez Ureña: Eugenio M. ${ }^{a}$..., pág. 483.

79 Méndez, José L.: "La actualidad del pensamiento de Eugenio M. ${ }^{a}$ de Hostos: a propósito del plebiscito", en Hostos: Sentido y proyección..., págs. 657-664, señala la vigencia, casi un siglo después, de "aquel primer intento de resolver nuestro problema colonial por medio de la consulta y la búsqueda de un consenso", pág. 659.

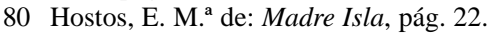

81 Ibídem, pág. 240. 
por el sistema americano de gobierno y reformara la instrucción pública. El resultado de todo esto sería, como señala el puertorriqueño José Luis Méndez, "una transfiguración de nuestro país en un coeficiente de civilización universal", ${ }^{82}$ ideas que vierte en numerosos artículos en la prensa de la isla: El Combate, Estrella Solitaria, La Nueva Era de Ponce, El Demócrata de Cayey, América, El Imparcial, La Nueva Bandera, El Amigo del Obrero, El Porvenir de Borinquen de Mayagüez y, por supuesto, de San Juan La Correspondencia de Puerto Rico.

Todavía en el último otoño del siglo XIX, consumadas tantas cosas en las Antillas, Hostos muestra la resignación esperanzada de quien confía, sin embargo, en la facción antiexpansionista, moderna y civilizadora de la vida americana. La política norteamericana en Puerto Rico, "mano de hierro en guante de seda" en palabras de uno de sus cónsules, fue asimilada por Hostos, cuando en calidad de comisionado por la isla junto a Julio J. Henna, Manuel Zeno Gandía y Rafael del Valle, se reunió con el presidente norteamericano a fin de exponerle ciertas demandas. ${ }^{83}$ "Lo que pediremos al Congreso de los Estados Unidos — señalan los miembros de la Comisiónserá, no que nos ponga en aptitud de federarnos o de independizarnos, sino de hacer constar en el plebiscito y por medio del plebiscito, las personalidades de nuestra patria". Las declaraciones en la prensa traslucen otros elementos inherentes al nuevo orden de cosas: "Por supuesto, [los puertorriqueños] esperan ser tratados como si fuésemos un hermano menor que debe ir a la escuela a aprender y que debe respetar al hermano mayor hasta que cuando hayamos crecido y hayamos sido educados en el gobierno propio podamos llegar a ser parte del pueblo americano y no permanecer por siempre sus subordinados". ${ }^{84}$ Una de las conclusiones de Hostos no es baladí: "Por mi parte y para mi caso personal he sacado en limpio que es una torpeza no hablar con fluencia el inglés". ${ }^{85}$

La trampa del gigante de la modernización estaba tendida porque se aceptaba de antemano la evidente intervención norteamericana, y la exigencia puertorriqueña se reducía al plebiscito para confirmar la aceptación del gobierno temporal y la fijación del tiempo de duración. "El plebiscito

82 Méndez: “La actualidad del pensamiento...", en Hostos: Sentido y proyección..., pág. 663.

83 Éstas eran en esencia: derechos y gobiernos (civil), concesiones económicas (libre cambio), concesiones educacionales (educación y fomento de la población puertorriqueña), enseñanza agrícola y concesiones militares (reducción fuerzas de Estados Unidos y creación de una milicia puertorriqueña).

84 Entrevista concedida a The Press, Nueva York. En E. M. ${ }^{a}$ de Hostos: Madre Isla, págs. $351-352$.

85 Henríquez Ureña: Eugenio M. ${ }^{a} . .$, pág. 490. 
—dirá Hostos-, es política alta, noble, digna, previsora y permanente, que los puertorriqueños adoptarán como política única del momento, como política de todos los puertorriqueños, de todos los que amen la dignidad de la tierra en que crecieron, de todos los que no se contentan por suspirar el advenimiento de una patria hecha por otros y quieren fabricarla por sí mismos sobre el cemento berroqueño del derecho". ${ }^{86}$

Dos años más tarde, el inicio de vida independiente en Cuba es visto por Hostos "como hora de sombría meditación más que hora de esperanzas luminosas". Sin embargo, esta "obra dudosa que empiezan hoy los cubanos a llevar a cabo", caracterizada por la mediatización norteamericana le parece que puede tener también un efecto benefactor: "con los cuatro años de limpieza que les han impuesto los yankees, limpiándoles sus ciudades a fuerza de trenes de limpieza y limpiándoles el cerebro a fuerza de reformas escolares, lícito es temer por Cuba un poco menos de lo que hay que temer por el resto de continente y del archipiélago hispanoamericano". En estas mismas páginas Hostos parece vaticinar un futuro de mayor libertad para Cuba que, en parte, la revolución de 1959 brindó:

"Ganosos de civilización, como ningún otro pueblo de nuestro origen, los cubanos
han sido los únicos hispanoamericanos que han tenido puestos los ojos en donde con-
viene a los que llevan el viaje a que están predestinados los pueblos de nuestro archi-
piélago y continente: en vez de estar mirando boquiabiertos hacia Europa, han esta-
do a América. Esto ha equivalido a mirar hacia el destino propio y no al ajeno". ${ }^{87}$

De alguna manera Hostos es ejemplo de una contradicción no patente en la época que nos ocupa, pero que el posterior desarrollo de los acontecimientos ha evidenciado; es una referencia a su idea de que el modelo de desarrollo norteamericano era un medio de resistir al propio imperialismo americano. Idea destinada al fracaso pero que, al menos él, tuvo la clarividencia de intentar resistir desde presupuestos netamente americanistas y luchando, desde su utopismo, contra el regionalismo de las nuevas repúblicas y por la unidad de acción y la solidaridad de toda América Latina. No hay que olvidar que el sentido último de su lucha vital es la independencia de las Antillas y el sueño de una confederación no sólo en el Caribe sino en toda América, incluyendo a los Estados Unidos. Desde esta postura idealista sueña con revalorizar la imagen de Latinoamérica tenida como cultura inferior dentro de los parámetros del discurso dominante.

86 Ibídem, págs. 20-21.

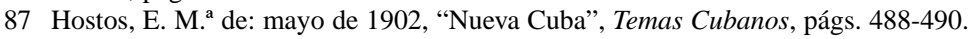

